\title{
Production of Prevalence and Pattern of Substance Abuse Amongst Principal in Private Pharmacy Institutions in a Rural Community, India
}

\author{
Rahul Hajare* \\ Indian Council of Medical Research, India
}

Received: 眥 July 23, 2018; Published: 眥July 26, 2018

*Corresponding author: Rahul Hajare, Indian Council of Medical Research, India, Email: rahulhajare@rediffmail.com

\section{Abstract}

Background: Principals in private pharmacy institutions are in their youthful age, prone to peer pressure and can easily resorts to social vices such as illicit drug use. Since youths are the bedrock of the society, curtailing these social vices will keep the community healthy.

Aim: To determine the prevalence and pattern of substance abuse among principals in private pharmacy institutions in rural community with a view to minimizing the effects of substance abuse among them.

Methods: A descriptive cross-sectional study was conducted among 164 principals in private pharmacy institutions in rural. Cochrane formular for descriptive cross-sectional study was used factors responsible for substance abuse. Participants were selected and all principals in private pharmacy institutions in the study area have included in the study, but multistage sampling technique has used to select the participants. Prevalence has determined by getting the percentage of the respondents who were involved in illicit drug use. Data were analysed with the aid of IBM-SPSS version 21.0. Results have presented in tables, frequency and charts [1,2].

Results: All the 164 Principals in private pharmacy institutions selected for the study participated; giving a response rate of $100 \%$. About two-third (66.5\%) of the respondents were within the age group of 45-55 years. 58.5\% of them were males and most (96.3\%) of them were local. Most of the respondents' principals (87.2\%) were married. And of the total number of respondents, $140(85.4 \%)$ resides with their PHD students while $11.6 \%, 2.4 \%$, and $0.6 \%$ of them resides with a guardian, extended family member and siblings respectively. A few $17(10.4 \%)$ of the respondents abuse drugs and the drugs commonly abused include Cigar $23.5 \%$, alcohol 41.2\%, Ghutaka 11.8\%, Cigarette 17.6\%, and tobacco 5.9\% [3]. Reasons for substance abuse as narrated by respondents include: Peer pressure $41.2 \%$, depression $5.9 \%$ and coping mechanism $41.2 \%$. Other reasons given include curiosity $5.9 \%$, and influence of media $5.9 \%$.

Conclusion: The prevalence of substance abuse among the principals in private pharmacy institutions studied was $10.4 \%$ and substances commonly abused among them include Cigar $23.5 \%$, alcohol $41.2 \%$, Ghutaka $11.8 \%$, cigarette $17.6 \%$ and tobacco 5.9\%. Factors responsible for substance abuse as revealed by respondents include: Peer pressure, depression, copping mechanism, curiosity and influence from the media $[4,5]$.

\section{Recommendation}

If do a cracking in mouth or experience pain during talking, contact your physician. Acquire sufficient knowledge for healthier life. Read textbook of anatomy and physiology from reputed authors. Check cross references from study related paper and research [6]. Choose vegetarian food and bed time food for improvement of

metabolism [7]. Prefer yoga from yoga instructor. Attend college as per time table, attempt duties by your own vehicle to reduce the risky behaviour, prepare time table and lunch time in accordance with human physiology. Make a practice for zero curse words in meetings. Zero corruption for staff approvals [8]. 


\section{Acknowledgements}

This study has been guided under the supervision and guidance of Renowned Immunologist Respected Dr. Ramesh S. Paranjape, Long-Time NARI Director India.

\section{References}

1. Rahul Hajare (2017) Can Otolaryngology Capture Window Cancer in Middle Adulthood? Ann Clin Lab Res 5(4): 205.

2. Rahul Hajare (2017) The Aggression is an Early Cause of Cancer. A Narrative Review of Classical to Modern Scientific Literature. Chronicle Med Surg 1(2): 67-68.

3. Rahul Hajare (2018) Lead Developer Angular and Effect of Force by Side Chain of Suicide Molecule in HIV AIDS Drug Discovery. Journal of Pharmaceutical Research and Reviews.
4. Rahul Hajare (2018) Safe Sex: The True Principal Health? Medical Research and Clinical Case Reports 1(2): 79-81.

5. Rahul Hajare (2018) Safe sex: the train your mind (revise). Gen Med Open 2(2): 1-2.

6. Rahul A Hajare (2018) 909090 Formulas and Symptoms of Adrenal Fatigue Syndrome (AFS) of Adult Men. Orthop \& Spo Med Op Acc J 1(3).

7. Rahul Hajare (2018) An Attempt to Eradicate Alcohol Dependency from Adult Men in Service Privately Managed Pharmaceutical Institutions in India. Toxicology and Applied Pharmacology Insights 1(1): 180001.

8. Rahul H (2018) Indian Women, Trauma and Hydroxyl Drugs Dependency: Connections and Disconnections in Heart Disease for Women. Int J Curr Innov Adv Res 1(2): 1-2.
To Submit Your Article Click Here:

This work is licensed under Creative

Commons Attribution 4.0 License

DOI: $10.32474 /$ AOICS.2018.03.000163

Submit Article

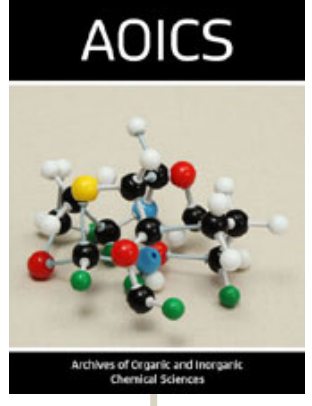

\section{Archives of Organic and Inorganic} Chemical Sciences

\section{Assets of Publishing with us}

- Global archiving of articles

- Immediate, unrestricted online access

- Rigorous Peer Review Process

- Authors Retain Copyrights

- Unique DOI for all articles 